\title{
Growth and Reproductive Success under Saline Conditions of Three Plantago Species with Different Levels of Stress Tolerance
}

\author{
Mohamad Al HASSAN ${ }^{1}$, Andrea PACURAR ${ }^{1,3}$, Alexandra GASPAR ${ }^{1,3}$, \\ Oscar VICENTE ${ }^{1}$, Monica BOSCAIU ${ }^{2 *}$
${ }^{1}$ Instituto de Biologia Molecular y Celular de Plantas (UPV-CSIC), Universitat Politécnica de València, CPI, edificio 8E, Camino de Vera s/n, 46022 Valencia,Spain; mohamad_al_hassan@live.com,ovicente@ibmcp.upv.es
${ }^{2}$ Instituto Agroforestal Mediterráneo (UPV), Universitat Politècnica de València, CPI, edificio 8E, Camino de Vera s/n,
46022 Valencia, Spain; mobosnea@eaf.upv.es ( ${ }^{*}$ corresponding author)
${ }^{3}$ Permanent address: University of Agricultural Sciences and Veterinary Medicine, Faculty of Horticulture, 3-5 Manastur Str., 400372 Cluj-Napoca,Romania;pacurar.andrea@yahoo.com,andragaspar@yahoo.com

\begin{abstract}
Salt stress responses were studied in three Plantago species (P. crassifolia, P. coronopus and P. major), with different levels of salt stress tolerance, at growth and reproductive stages of the life cycle. Plants were treated with increasing salt concentrations $(0,100,200$ and $400 \mathrm{mM} \mathrm{NaCl})$ under controlled conditions in the greenhouse. Fresh biomass, leaf length and reproductive parameters related to flowering were analysed. To evaluate the reproductive success of salt-stressed plants, seeds produced after two months of treatment were sampled, and the mean number of seeds per plant and mean seed weight per treatment were determined. Seeds were germinated in vitro and seed and seedling quality were assessed by determining germination percentages and rates, length of radicle, hypocotyl, cotyledonary leaves, and the angle of cotyledonary leaves. The 'seedling vigour index' was also calculated. Vegetative (fresh weight and leaf length) and reproductive traits (number of inflorescences, scape and spike length, mean number of seeds per spike and mean seed weight) were less affected by salinity in the more stress tolerant species $P$. crassifolia and $P$. coronopus than in $P$. major. Percentage and velocity of germination of seeds produced by plants grown under saline treatments were similar in all species; however seedling development was less successful in $P$. major, as shown by length of the radicle, hypocotyl and cotyledonary leaves. The relative sensitivity to salt of the investigated Plantago species correlated with their distribution in nature: $P$. major, never present in saline environments, was much more affected by salt than its halophytic counterparts, while $P$. crassifolia, which grows in saline habitats, exhibited the most efficient responses to salt stress, especially at the early seedling development stage.
\end{abstract}

Keywords: flowering, glycophytes, halophytes, reproductive success, seed germination, seedling development, seedling vigour

\section{Introduction}

Soil salinity is an environmental factor that significantly affects the distribution of plants in their natural ecosystems and it is one of the major threats for agriculture. According to FAO (2008), more than 800 million ha of land worldwide are affected by salinity. The extension of saline soils is increasing by approximately $1 \%$ each year due to poor rainfall, increasing temperatures with higher evaporation of water from soil, weathering of rocks, and anthropogenic alterations, such as irrigation with saline water, or the abusive and indiscriminate use of fertilizers (Flowers and Yeo, 1995; Munns and Tester, 2008; Rengasamy, 2010).

The immense majority of terrestrial plant species and all major crops belong to the category of glycophytes, or plants that cannot survive in conditions of (relatively) high soil salinity. On the contrary, halophytes include species that are able to survive and complete their life cycle in the presence of salt concentrations of at least $200 \mathrm{mM} \mathrm{NaCl}$ (Flowers et al., 1986; Flowers and Colmer, 2008). Halophytes represent a small group of plants of only about 600 species that belongs to a few genera and families, which have adapted to saline ecosystems under harsh environmental conditions, thus avoiding competition with glycophytes (Flowers et al., 1986).

Tolerance to salt stress involves complex mechanisms since numerous interactions take place between stress factors and the molecular, biochemical and physiological processes affecting plant development (Ashraf and Foolad, 2007). Halophytes would seem to be the most appropriate biological material to investigate these interactions; yet most experimental studies on plant responses to salt stress and salt tolerance mechanisms have been carried out on glycophytes, 
especially on model plants such as Arabidopsis thaliana (Zhu, 2000). The limitations of this approach and the necessity to increase ecophysiological research on halophytes have been recently discussed (Gil et al., 2013; Grigore et al., 2011). Most mechanisms of response to abiotic stress appear to be conserved in all plants, but their efficiency must largely vary among species so that they are effective enough to confer salt tolerance only in halophytes. Differences between glycophytes and halophytes seem to be the result of changes in the expression of the same basic packages of genes (Xiong and Zhu, 2002; Zhu, 2000, 2001); thus such differences are quantitative in nature rather than qualitative (Flowers et al., 1986; Greenway and Munns, 1980; Vicente et al., 2004; Zhu, 2001).

A very useful approach to gain a better comprehension of the concepts of 'stress responses' $v$ s. 'stress tolerance' or 'stress adaptation', which are often confused, would be to carry out comparative studies on species closely related taxonomically, hence with a similar genetic background, but with different degrees of stress tolerance (Gil et al., 2013). The genus Plantago with more than 200 species and 483 taxa in all (Tutel $e t$ al., 2005), of which at least 20 species are considered halophytes, is one of the most suitable for such studies. Despite the relatively large number of papers that have dealt with one or several Plantago species, there are no comparative studies on their responses to salt stress at a crucial stage in the plant's life cycle, which is reproduction. Flowering, seed set, but mostly seed germination and seedling development, represents a bottleneck in the life cycle of those plants confronted by adverse environmental conditions. Germination is strongly inhibited by high salinity, even in most halophyte species, so many plants that have adapted to saline environments have developed strategies to postpone germination until the rain season, when soil salinity decreases. Therefore, salt tolerance at the specific stages of reproductive development and, mostly, seed germination, is probably one of the critical factors controlling plant distribution in habitats of different soil salinity.

A study into the effects of salt stress on germination in three Plantago halophytes (P. coronopus, $P$. crassifolia, and $P$. microrrbiza) showed that it was affected strongly by salinity and that, in all three species, there is an initial dormancy period, which is longer at higher temperatures (Luciani $e t$ al., 2001). Dormancy is a common trend in halophytes, and seeds of numerous Mediterranean halophytes actually germinate in autumn when salinity is alleviated by abundant rainfall that washes out salts from the upper soil layers.

Although there are numerous publications on the physiological and biochemical responses to salt stress in species of the genus Plantago, the flowering and quality of the seeds produced by stressed plants have been analysed only in P. crassifolia (Boscaiu et al., 2005). The present work analyses responses to saline stress at vegetative growth and reproductive stages in three Plantago species. Plantago coronopus $\mathrm{L}$. is a cosmopolitan annual or biennial present in a wide range of variable habitats, mostly on disturbed lands, waste places, or littoral sand dunes. It is considered an indicator of the salinisation of marginal soils since it tolerates moderate salt stress; its growth appears to be even slightly stimulated by low salt concentrations (Koyro,
2006). Yet Luciani $e t$ al. (2001) found that $P$. coronopus seed germination was the most salt-sensitive among the Plantago halophytic species they studied. Taxonomically, it belongs to the section Coronopus (Lam \& DC) Dietr. of the subgenus Coronopus (Lam. \& DC.) Rahn, which includes 11 Mediterranean species (Rahn, 1996).

Plantago crassifolia Forssk. is a common perennial halophyte in littoral salt marshes and other saline habitats in the Mediterranean region. Previous studies (Boscaiu et al., 2005; Vicente et al., 2004) have shown the moderate salt tolerance of this species: it grows optimally in the absence of salt, and a drastic reduction in seed quantity and quality was observed under high salinity conditions. In natural environments, $P$. crassifolia appears only in areas with moderate salinity, on salt marsh borders, but never in strongly saline areas dominated by highly tolerant halophytes. From the taxonomic point of view, $P$. crassifolia is closely related to $P$. coronopus, which belongs to the same section.

Plantago major $\mathrm{L}$. is a perennial (seldom annual) glycophyte, with origins in Eurasia and North Africa but naturalised throughout the world and considered as an important medicinal plant. It is much less salt tolerant than the two previous species and requires moderate humidity. Taxonomically, it is not so closely related to $P$. crassifolia and $P$. coronopus, since it is included in the section Plantago of the subgenus Plantago, the largest within the genus, with 130 species worldwide (Rønsted et al., 2003).

The aim of this study was twofold. Firstly, to gain a better comprehension of the differences between mere responses and adaptations to stress in the three species. Secondly, to attempt and correlate the 'reproductive success' under high salinity conditions of these taxa with their distribution in nature. The paper compares the responses to salt of the three Plantago species during the growth and the reproductive stages, but it focuses mostly on seed production and seed and seedling quality as an expression of their relative reproductive success under salt stress conditions.

\section{Material and methods}

\section{Plant growth and salt treatments}

Seeds of $P$. crassifolia and $P$. coronopus were harvested in a salt marsh located in the Natural Park of La Albufera (Province of Valencia, Spain), and seeds of $P$. major were purchased from the company Spicegarden, EU.

The seeds of the three species under study were sown in seed trays containing a mixture of commercial peat and vermiculite (3:1), and were placed in a greenhouse with regulated temperatures of $17-23{ }^{\circ} \mathrm{C}$, a photoperiod of 16 hours, and $85 \%$ relative humidity. Twenty days after sowing, young plants were transferred to individual pots on the same substrate in which they were grown for four weeks; then treatments with increasing salt concentrations $(0,100$, 200 and $400 \mathrm{mM} \mathrm{NaCl}$ ) were applied. The number of plants for each treatment and species was 3-5, and irrigation was carried out twice a week by adding $1.5 \mathrm{~L}$ of salt solutions (or distilled water, for the non-stressed control plants) to each tray $(55 \times 40 \mathrm{~cm})$, which contained 12 standard pots (11 cm in diameter). After two months, all the plants were 
182

harvested and the vegetative parts were weighed individually on a precision balance. The length of the longest leaf was also measured. The reproductive parts of these plants were separated and used for further analysis.

\section{Analysis of the plants' reproductive traits}

The total number of spikes was recorded for each plant, and the lengths of floral scapes and spikes were measured. Seed set was estimated by counting and weighing seeds from approximately half the fertile spikes per treatment and species.

The quality of the seeds produced by the plants submitted to salt and control treatments was assessed by determining their germination capacity. Four replicas of 25 seeds per species and per treatment were placed in standard Petri dishes ( $9 \mathrm{~cm}$ in diameter), with cotton and filter paper moistened with $15 \mathrm{~mL}$ of distilled water; plates were sealed with parafilm to avoid evaporation and were incubated in a growth chamber at $25^{\circ} \mathrm{C}$ under a 16 -hour photoperiod. The number of germinated seeds, considered upon radicle emergence, was counted daily over a two-week period. Germination capacity was expressed as the final percentage of germination and the germination rate as MGT (mean germination time) according to the formula provided below (Ellis and Roberts, 1981):

$\mathrm{MGT}=\sum \mathrm{D} \mathrm{n} / \sum \mathrm{n}$,

Where $\mathrm{D}$ are the days from the beginning of the germination test, and $\mathrm{n}$ is the number of seeds newly germinated on day $\mathrm{D}$.

The seedlings were analysed using ImageJ software (Rasband 1997-2012). The length of the radicle, hypocotyl and cotyledonary leaves, and the angle between cotyledons, were measured in 60 randomly selected, 12 days-old seedlings per species and per treatment. In addition, seedlings were weighed on a precision balance. Seedling Vigour Index (SVI) was calculated by the following formula (Abdul-Baki and Anderson, 1973):

SVI = Germination percentage $\mathrm{x}$ [Mean root length $(\mathrm{mm})+$ Mean hypocotyl length $(\mathrm{mm})]$.

Since $P$. coronopus plants that were watered without salt did not flower over the two-month treatment, the seeds from the initial stock were used as a control for the germination assay and seedlings measurements.

\section{Soil analysis}

Electrical conductivity of the substrate was checked at the end of treatments. Soil samples were taken from 3 pots per treatment, air-dried and then passed through a $2-\mathrm{mm}$ sieve. A soil: water (1:5) suspension was prepared in distilled water and stirred for $60 \mathrm{~min}$ at $600 \mathrm{u} / \mathrm{min}$ at $21^{\circ} \mathrm{C}$. Electric conductivity was measured with a Crison Conductivity meter 522 and expressed in $\mathrm{d} S / \mathrm{m}$.

\section{Statistical analysis}

Data were analysed using SPSS, v. 16 and SYSTAT v. 12. A Levene test was applied to check whether the requirements of the analysis of variance (ANOVA) were accomplished. Germination percentages were normalized by arcsine transformation prior to the analysis of variance. Radicle, hypocotyl and cotyledonary leaves' lengths were transformed into percentages, considering values in control treatments as $100 \%$ in each species. The significance of the differences among treatments and among species was tested by applying a one-way ANOVA, at a confidence level of 95\%. When the ANOVA null hypothesis was rejected, posthoc comparisons were performed by the Tukey test. A linear fitting was applied to correlate the soil EC with the concentration of the saline solutions applied to the pots.

\section{Results and discussion}

Electrical conductivity of the substrate increased with the salt treatments in the three species (Fig. 1). The $\mathrm{EC}_{1: 5}$ of substrate in the treatment with $400 \mathrm{mM} \mathrm{NaCl}$ was about 13-fold higher than that registered in the control, for the three species. This increase was highly correlated with the

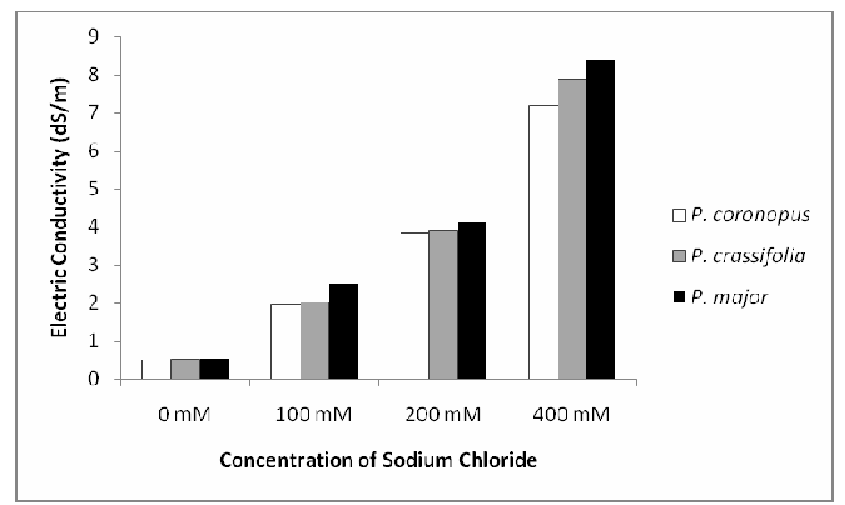

Fig. 1. Electric conductivity $\left(\mathrm{EC}_{1: 5}\right)$ of the substrate after two months of salt treatments

saline solution applied, with high $\mathrm{R}^{2}$ in the linear fitting in all species ( 0.92 in $P$. coronopus, 0.98 in $P$. crassifolia and 0.91 in P. major).

Sodium chloride treatments inhibited growth in a concentration-dependent manner in the three species under study. Maximal fresh weight (FW) was recorded in the control plants of the most vigorous species, $P$. major, which drastically decreased about 10 -fold in the plants treated with $400 \mathrm{mM} \mathrm{NaCl}$. The fresh weight of $P$. coronopus and $P$. crassifolia also decreased, but only by about 4- and 5.5-fold, respectively, at the same $\mathrm{NaCl}$ concentration (Fig. 2). These observations are consistent with the ecological requirements

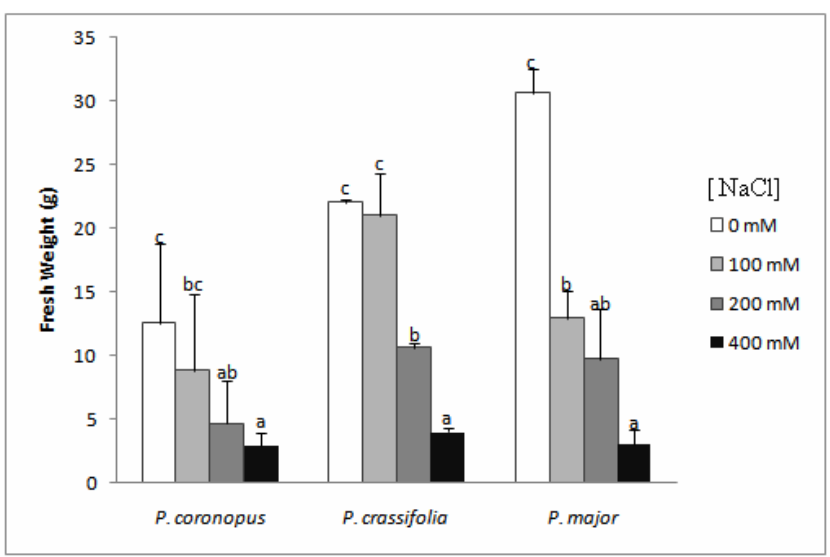

Fig. 2. Fresh weight of plants of Plantago coronopus, $P$. crassifolia and $P$. major treated for two months with the indicated $\mathrm{NaCl}$ concentrations. Same letters indicate homogeneous groups among treatments for each species 
183

of the three species since $P$. major, the most affected by salt, is precisely the species that is never confronted with salinity in its natural environment.

Another parameter that is used to assess the effect of salinity on plant growth is the length of the longest leaf, which is generally affected by salt (Fig. 3). Indeed, a reduction in the longest leaf length was observed with increasing $\mathrm{NaCl}$ concentrations in the three taxa, but no

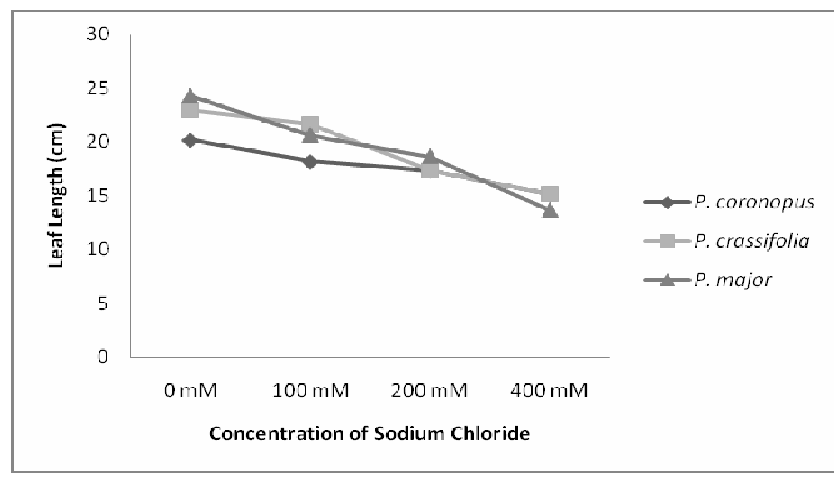

Fig. 3. Length of the longest leaf in the plants of Plantago coronopus, $P$. crassifolia and $P$. major treated for two months at the indicated $\mathrm{NaCl}$ concentrations

significant differences were found among them (1.9-fold in $P$. major, 1.5-fold in $P$. crassifolia and 1.3-fold in $P$. coronopus). These data, related to vegetative growth, are similar to those previously reported in $P$. crassifolia (Vicente et al., 2004), but no stimulation of growth at low salinity levels was detected in $P$. coronopus, contrarily to what Koyro described (2006).

Effects of salinity on the floral characters were diverse among species. In $P$. coronopus, only the plants treated with 200 and $400 \mathrm{mM} \mathrm{NaCl}$ produced flowers (Tab. 1).

In $P$. crassifolia, the mean number of spikes per plant increased in the treatments with 100 and $200 \mathrm{mM} \mathrm{NaCl}$, as reported in previous studies (Boscaiu et al., 2005); at 400 $\mathrm{mM} \mathrm{NaCl}$ the average number of spikes was smaller, similarly to that of the control (Tab. 1), whereas in a previous study (Boscaiu et al., 2005) plants did not flower at all after five months of treatment at the same salt concentration. Such differences may be explained by the differences in the experimental conditions of plant growth, mostly regarding temperature and photoperiod. Salinity can induce inhibition or stimulation of flowering, and early or delayed flowering, depending on the plant species (Grigore et al., 2011). The 'survival through the next generation' strategy can occur by both early flowering (Blanvillain $e t$ al.,

Tab. 1. Effects of increasing saline solutions on the traits related to reproductive success in Plantago crassifolia, P. coronopus and P. major. Mean \pm SD values are shown. Same letters indicate homogeneous groups among treatments for each species, n.d. not determined since plants did not flower, and ${ }^{*}$ seeds from the initial stock

\begin{tabular}{|c|c|c|c|c|c|}
\hline Character & Species & Control & $100 \mathrm{mM} \mathrm{NaCl}$ & $200 \mathrm{mM} \mathrm{NaCl}$ & $400 \mathrm{mM} \mathrm{NaCl}$ \\
\hline \multirow[t]{3}{*}{ Spike number/plant } & P. crassifolia & $3.66 \pm 1.15^{\mathrm{a}}$ & $4.33 \pm 1.52^{\mathrm{ab}}$ & $6.66 \pm 1.52^{b}$ & $3.33 \pm 0.57^{\mathrm{a}}$ \\
\hline & P. coronopus & n.d. & n.d. & $1.66 \pm 0.57^{b}$ & $1.33 \pm 0.57^{b}$ \\
\hline & P. major & $7.66 \pm 3.21^{\mathrm{b}}$ & $5.66 \pm 1.15^{b}$ & $4.66 \pm 2.08^{\mathrm{ab}}$ & $1.33 \pm 0.57^{\mathrm{a}}$ \\
\hline \multirow[t]{3}{*}{ Scape length $(\mathrm{cm})$} & P. crassifolia & $24.55 \pm 9.02^{c}$ & $18.89 \pm 7.52^{b}$ & $11.32 \pm 3.18^{\mathrm{a}}$ & $7.09 \pm 1.41^{\mathrm{a}}$ \\
\hline & P. coronopus & n.d. & n.d. & $34.30 \pm 8.04^{b}$ & $10.00 \pm 3.08^{\mathrm{a}}$ \\
\hline & P. major & $28.34 \pm 4.19^{\mathrm{d}}$ & $23.33 \pm 1.72^{c}$ & $17.54 \pm 1.35^{b}$ & $8.81 \pm 1.41^{\mathrm{a}}$ \\
\hline \multirow[t]{3}{*}{ Spike length $(\mathrm{cm})$} & P. crassifolia & $5.15 \pm 2.42^{c}$ & $4.84 \pm 1.5^{c}$ & $3.00 \pm 0.63^{b}$ & $2.00 \pm 0.38^{\mathrm{a}}$ \\
\hline & P. coronopus & $6.70 \pm 1.78^{b}$ & n.d,. & $6.70 \pm 1.78^{b}$ & $1.62 \pm 0.47^{\mathrm{a}}$ \\
\hline & P. major & $10.42 \pm 2.94^{c}$ & $8.12 \pm 1.38^{\mathrm{b}}$ & $7.37 \pm 0.9^{b}$ & $3.50 \pm 0.75^{\mathrm{a}}$ \\
\hline \multirow[t]{3}{*}{ Seed number/spike } & P. crassifolia & $88.71 \pm 15.33^{c}$ & $72.83 \pm 2.75^{b}$ & $70 \pm 9.05^{b}$ & $48.66 \pm 3.05^{\mathrm{a}}$ \\
\hline & P. coronopus & n.d. & n.d. & $289.5 \pm 27.57^{b}$ & $41 \pm 29.69^{\mathrm{a}}$ \\
\hline & P. major & $1369.20 \pm 439^{b}$ & $1345.83 \pm 230^{b}$ & $1358.33 \pm 281^{b}$ & $512.85 \pm 291.0^{\mathrm{a}}$ \\
\hline \multirow[t]{3}{*}{ Seed weight (mg) } & P. crassifolia & $0.49 \pm 0.10^{c}$ & $0.49 \pm 0.07^{c}$ & $0.41 \pm 0.10^{\mathrm{b}}$ & $0.39 \pm 0.11^{\mathrm{a}}$ \\
\hline & P. coronopus & $0.34 \pm 0.02^{\mathrm{c} *}$ & n.d. & $0.27 \pm 0.02^{b}$ & $0.17 \pm 0.01^{\mathrm{a}}$ \\
\hline & P. major & $0.39 \pm 0.02^{c}$ & $0.33 \pm 0.02^{b}$ & $0.28 \pm 0.01^{\mathrm{a}}$ & $0.26 \pm 0.01^{\mathrm{a}}$ \\
\hline \multirow[t]{3}{*}{ Percentage of germination } & P. crassifolia & $98.40 \pm 4.00^{\mathrm{b}}$ & $84.00 \pm 0.00^{\mathrm{a}}$ & $81.00 \pm 2.00^{a}$ & $89.00 \pm 11.00^{\mathrm{a}}$ \\
\hline & P. coronopus & $96.00 \pm 4.60^{a^{*}}$ & n.d. & $99.00 \pm 2.00^{\mathrm{ab}}$ & $92.00 \pm 0.00^{\mathrm{a}}$ \\
\hline & P. major & $99.00 \pm 2.00^{\mathrm{a}}$ & $98.00 \pm 4.00^{\mathrm{a}}$ & $97.00 \pm 6.00^{\mathrm{a}}$ & $98.00 \pm 2.30^{\mathrm{a}}$ \\
\hline \multirow[t]{3}{*}{ MGT (days) } & P. crassifolia & $4.79 \pm 0.60^{a}$ & $4.94 \pm 0.20^{\mathrm{a}}$ & $4.66 \pm 0.40^{\mathrm{a}}$ & $5.14 \pm 1.10^{\mathrm{a}}$ \\
\hline & P. coronopus & $2.92 \pm 0.30^{\mathrm{a}^{*}}$ & n.d. & $2.76 \pm 0.40^{a}$ & $3.02 \pm 0.10^{\mathrm{a}}$ \\
\hline & P. major & $3.90 \pm 0.20^{\mathrm{a}}$ & $4.01 \pm 0.10^{\mathrm{a}}$ & $4.25 \pm 0.14^{\mathrm{a}}$ & $4.19 \pm 0.20^{\mathrm{a}}$ \\
\hline \multirow[t]{3}{*}{ Seedling weight (mg) } & P. crassifolia & $6.45 \pm 0.22^{b}$ & $6.32 \pm 0.01^{b}$ & $5.94 \pm 0.12^{b}$ & $5.22 \pm 0.26^{a}$ \\
\hline & P. coronopus & $5.07 \pm 0.06^{\mathrm{c} *}$ & n.d. & $3.57 \pm 0.01^{b}$ & $1.75 \pm 0.02^{\mathrm{a}}$ \\
\hline & P. major & $3.01 \pm 0.39^{\mathrm{b}}$ & $2.18 \pm 0.77^{\mathrm{ab}}$ & $0.98 \pm 0.36^{a}$ & $0.94 \pm 0.38^{a}$ \\
\hline \multirow[t]{3}{*}{ SVI } & P. crassifolia & 2438.352 & 1176.84 & 1109.70 & 954.08 \\
\hline & P. coronopus & $3901.44^{*}$ & n.d. & 3027.42 & 2650.52 \\
\hline & P. major & 2677.95 & 2132.48 & 1428.81 & 1209.32 \\
\hline \multirow[t]{3}{*}{ Cotyledonary leaves angle $\left({ }^{\circ}\right)$} & P. crassifolia & $69.54 \pm 17.81^{\mathrm{a}}$ & $94.20 \pm 31.98^{b}$ & $103.98 \pm 24.78^{b}$ & $98.15 \pm 30.50^{b}$ \\
\hline & P. coronopus & $67.58 \pm 16.45^{a^{*}}$ & n.d. & $76.53 \pm 13.86^{\mathrm{ab}}$ & $79.87 \pm 21.73^{b}$ \\
\hline & P. major & $45.41 \pm 13.99^{\mathrm{a}}$ & $53.42 \pm 18.72^{a}$ & $72.24 \pm 14.72^{b}$ & $75.10 \pm 22.90^{b}$ \\
\hline
\end{tabular}


184

2011) and an increase in the number of flowers produced, which is what we found in P. crassifolia and P. coronopus. On the contrary, the glycophyte $P$. major responded differently when exposed to salt stress. In this species, a concentration-dependent reduction of spike numbers was observed which was almost 6-fold at the highest salt concentration tested (Tab. 1).

The number of seeds produced by each species under different salinity conditions correlated well with the length of the spikes measured for the corresponding treatments, and decreased progressively with increasing external $\mathrm{NaCl}$ concentrations (Tab. 1). It is worth mentioning that in all cases, $P$. major, which is the most vigorous of the studied species, produced a considerably larger number of seeds in comparison with the other two. The mean mass of the seeds was also determined, and it became evident that those produced by control, non-stressed plants had the highest mass, which decreased in all three species with increasing salt concentrations (Tab. 1).

These findings show that, even though salinity may stimulate flowering, it clearly has a negative, concentrationdependent effect on reproduction in the three species under study: $\mathrm{NaCl}$ diminished the quality of the flowers produced, which were smaller and produced a reduced number and mass of seeds as compared with the controls grown in the absence of salt.

The quality of the seeds produced by the plants grown under different salinity conditions was assessed in in vitro germination tests, showing very high germination percentages $(>96 \%)$ in the control seeds of all three Plantago species, and the salt treatments of the mother plants did not lead to statistically significant changes in these values (Tab. 1). 'Mean germination time' (MGT) values differed for the seeds of the three species but, for each species, no significant differences were observed among the $\mathrm{NaCl}$ treatments (Tab. 1). On the contrary, the quality of the seedlings deriving from these seeds was clearly affected by the previous salt treatments of the mother plants. A significant loss of vigour of the seedlings with increasing salt concentrations, as estimated from the Seedling Vigour Index (SVI), was observed for the three Plantago species: when comparing the seeds produced by control plants and those from the plants watered with $400 \mathrm{mM} \mathrm{NaCl}$, SVI values decreased by about 1.5 -fold in $P$. coronopus, 2.5 -fold in $P$. crassifolia, and 2.2-fold in $P$. major (Tab. 1). The weight of the seedlings followed a similar pattern, that is, decreasing with increasing salt concentrations, but with clear differences between the investigated species (Tab. 1). The treatment of the mother plants with the highest salt concentration tested, $400 \mathrm{mM} \mathrm{NaCl}$, resulted in a reduction in seedling weight of about $20 \%$ ( $P$. crassifolia), $65 \%$ (P. coronopus), and $70 \%$ (P. major) of the corresponding controls. These results indicate that $P$. crassifolia is minimally affected by high salinity at the seedling stage when compared with the other two species. This finding supports the idea that it is the most salttolerant of the three, which is in agreement with the distribution observed in the nature of these Plantago taxa.

All the growth parameters analysed by the ImageJ programme (length of radicle, hypocotyl and cotyledonary leaves' angle and length) showed a clear pattern of variation,

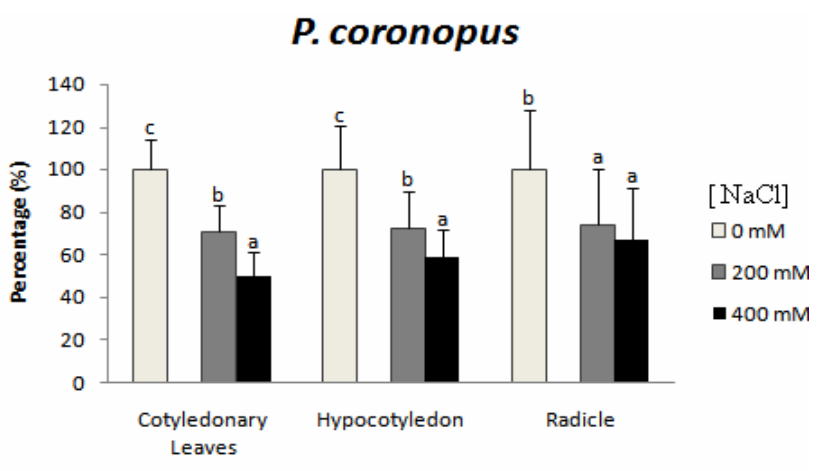

P. crassifolia

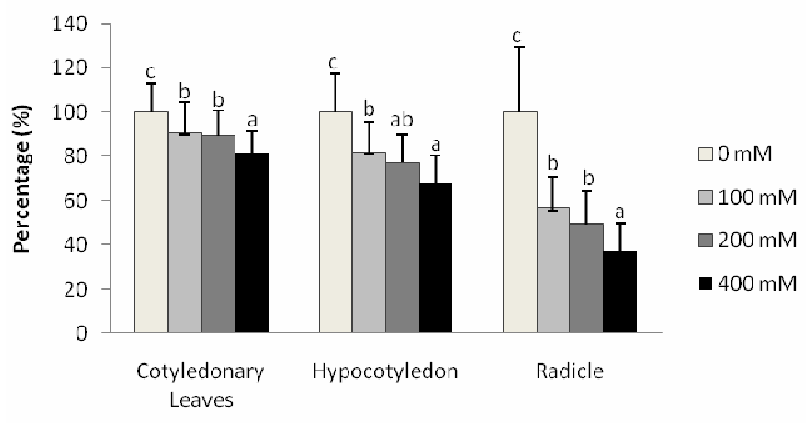

P. major

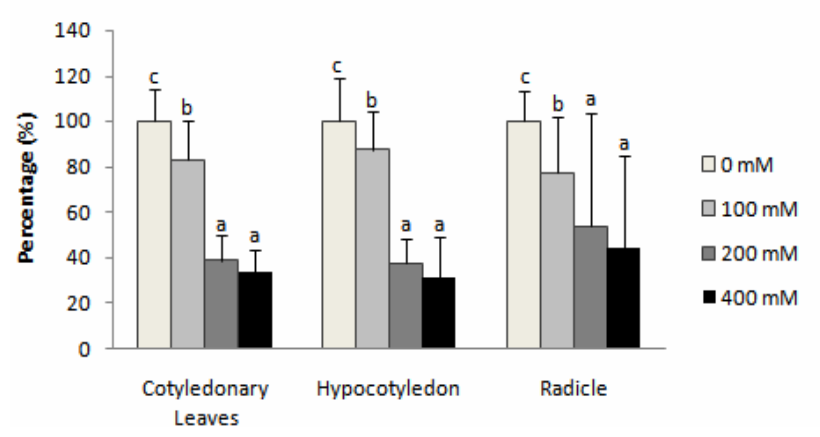

Fig. 4. Radicle, hypocotyle and cotyledon length reduction in 12 days-old seedlings obtained from seeds sampled from the plants treated for two months at the indicated $\mathrm{NaCl}$ concentrations. Percentages were calculated in relation to the controls' mean values which were considered $100 \%$. Same letters indicate homogeneous groups among treatments for each species

which decreased in parallel to the increase in the $\mathrm{NaCl}$ concentration of the treatments applied to the mother plants (Fig. 4 and Tab. 1).

The most marked reduction in hypocotyl and cotyledon length was observed in P. major, and the least marked one in $P$. crassifolia, which once again is in agreement with the relative salt tolerance of these taxa. However, it was not possible to find a similar correlation in the salt-dependent decrease in radicle size (Fig. 4). Although the germination rates were very high in $P$. major, even for the seeds produced by those plants treated with 200 and $400 \mathrm{mM}$ of NaCl, their seedlings were of poor quality; in almost half of them, cotyledons did not emerge as their development was blocked after radicle emergence (Fig. 5). 

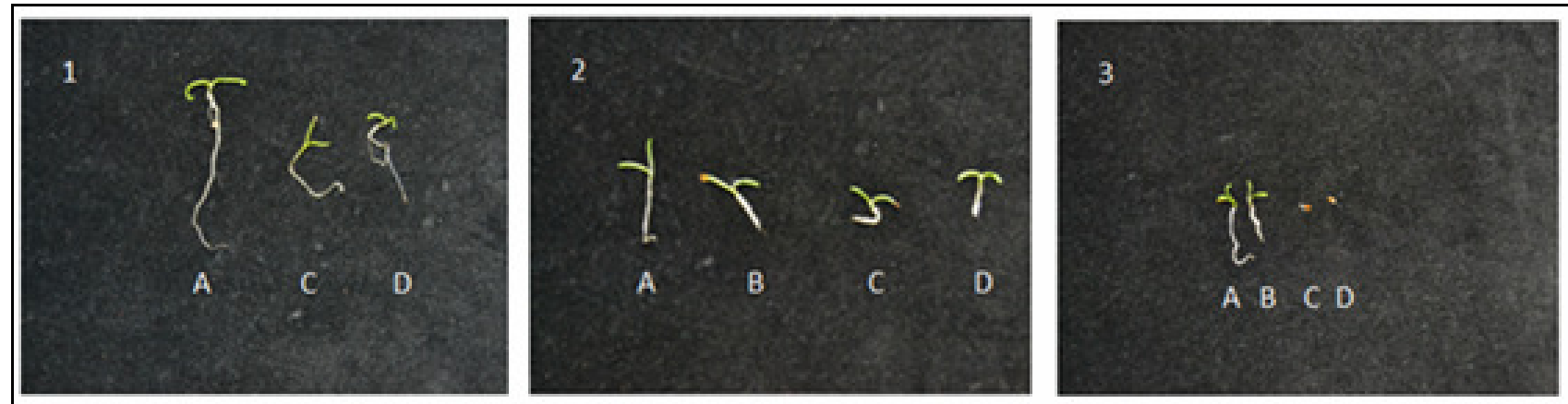

Fig. 5. Seedlings of Plantago coronopus (1), P. crassifolia (2) and P. major (3) obtained from the plants treated for two months with distilled water (A), $100 \mathrm{mM} \mathrm{NaCl}$ (B), $200 \mathrm{mM} \mathrm{NaCl}$ (C) or $400 \mathrm{mM} \mathrm{NaCl}$ (D)

The angle of cotyledonary leaves is a seedling characteristic that can be considered an early predictor of the growth rate. Lower et al. (1978) reported that cucumber (Cucumis sativus) seedlings which displayed their cotyledons in an upward position (smaller angle) grew faster than the plants which displayed their cotyledons in a downward position (larger angle). An upward cotyledon angle also correlated with the increase in plant height, node number and fresh weight at later developmental stages. In the analysed seedlings of the Plantago species, cotyledon angles (Tab. 1) increased in parallel to the increase in salinity, which affected mother plants, suggesting that stress conditions may negatively affect growth in the next generation.

In summary, salinity affected several growth and reproductive traits in the three Plantago species studied in the present work. The plants grown under salt stress conditions were less vigorous and their reproductive success was clearly affected by salinity, but two different patterns were detected: one corresponding to the salt-tolerant $P$. coronopus and $P$. crassifolia on the one hand, and to the glycophyte $P$. major on the other. Fresh weight decreased with increasing salinity in all three species, but this reduction was much more marked in $P$. major than in $P$. coronopus or $P$. crassifolia. Salinity stimulated flowering in halophytes, while the number of spikes lowered in $P$. major by salt treatments, although the absolute number of spikes was greater in the latter species, which is the most vigorous. Seed set and mass of seeds were also reduced in the three species in response to increasing salinity. Although no significant effect was observed on the germination capacity of seeds, which was very high under all the conditions tested, growth of mother plants in the presence of increasing salt concentrations negatively affected the quality of the corresponding seedlings. Seedling size and weight reduced upon salt treatment, but the observed reduction was much more evident in the glycophyte $P$. major than in the halophytes $P$. crassifolia and $P$. coronopus. Most importantly, upon germination of the $P$. major seeds obtained from plants treated with high $\mathrm{NaCl}$ concentrations, inhibition of seedling development was observed at an early stage, after radical emergence, and cotyledons did not emerge in almost half the seedlings. When comparing the two halophytes, $P$. crassifolia showed stronger resistance to salt stress than $P$. coronopus, as indicated by a slighter decrease in seedling weight or in hypocotyl and cotyledon lengths.

\section{Conclusions}

The results presented herein allow distinguishing how related species with different levels of salt tolerance respond to high soil salinity conditions. They also suggest that the reproductive success of a particular species under salt stress conditions depends largely on its tolerance at the specific early seedling development stage. The different responses of the studied species under the controlled greenhouse conditions correlate closely with their ecology and distribution in nature. $P$. major behaves as a typical glycophyte - although it is not extremely sensitive to salt showing a very strong inhibition of vegetative growth and reproductive development, and low reproductive success, in conditions of salt stress; this species is never found in nature in saline habitats. When comparing the two Plantago taxa considered to be halophytes, our findings support the notion that $P$. crassifolia is more salt-tolerant than $P$. coronopus since its responses to salinity are more effective, especially at the early seedling development stage. This is also in agreement with their ecological characteristics, as only $P$. crassifolia is able to inhabit typical saline areas such as salt marshes.

\section{Acknowledgements}

Work in the UPV laboratories was funded by a grant to O.V. from the Spanish Ministry of Science and Innovation (Project CGL2008-00438/BOS), with contribution from the European Regional Development Fund. M.A.H. is a recipient of an Erasmus Mundus pre-doctoral scholarship financed by the European Commission (Welcome Consortium). A.P. and A.G. acknowledge the Erasmus fellowship programme for funding their stay in Valencia to carry out their Master Theses.

\section{References}

Abdul-Baki AA, Anderson JD (1973). Relationship between decarboxilation of glutamic acid and vigour in soybean seed. Crop Sci 13:222-226.

Ashraf M, Foolad MR (2007). Roles of glycine betaine and proline in improving plant abiotic stress resistance. Environ Exper Bot 59:206-216.

Blanvillain R, Wei S, Wei P, Kim JH, Ow DW (2011). Stress tolerance to stress escape in plants: role of the OXS2 zincfinger transcription factor family. EMBO J 30:3812-3822. 
186

Boscaiu M, Estrelles E, Soriano P, Vicente O (2005). Effects of salt stress on the reproductive biology of the halophyte Plantago crassifolia. Biol Plant 49:141-143.

Ellis RA, Roberts EH (1981). The quantification of aging and survival in orthodox seeds. Seed Sci Technol 9:373-409.

FAO (2008). Land and plant nutrition management service. <http://www.fao.org.ag/agl/agll/spush>.

Flowers TJ, Colmer TD (2008). Salinity tolerance in halophytes. New Phytol 179:945-963.

Flowers TJ, Hajibagheri MA, Clipson NJW (1986). Halophytes. Q Rev Biol 61:313-335.

Flowers TJ, Yeo AR (1995). Breeding for salinity resistance in crop plants: where next? Aust J Plant Physiol 2:875-884.

Gil R, Boscaiu M, Lull C, Bautista I, Lidón A, Vicente O (2013). Are soluble carbohydrates ecologically relevant for salt tolerance in halophytes? Funct Plant Biol 40:805-118.

Greenway H, Munns R (1980). Mechanisms of salt tolerance in non-halophytes. Annu Rev Plant Physiol 31:149-190.

Grigore MN, Boscaiu M, Vicente O (2011). Assessment of the relevance of osmolyte biosynthesis for salt tolerance of halophytes under natural conditions. Eur J Plant Sci Biotechnol 5:2-19.

Koyro H-W (2006). Effect of salinity on growth, photosynthesis, water relations and solute composition of the potential cash crop halophyte Plantago coronopus (L.). Environ Exp Bot 56:136-146.

Lower RL, Pharr DM, Smith OS, Sox HN (1978). Cotyledon angle as a predictor of growth rate of cucumber plant. Euphytica 27:701-706.
Luciani F, Cristaudo A, Aricó D. (2001). Germination ecology of three Plantago L. species living in a saline environment. Plant Biosyst 135:213-221.

Munns R, M. Tester (2008) Mechanisms of salinity tolerance. Annu Rev Plant Biol 59:651-681.

Rahn K (1996). A phylogenetic study of the Plantaginaceae. Bot J Linn Soc 120:145-198.

Rasband WS (1997-2012) ImageJ. U S National Institutes of Health. http://rsb.info.nih.gov/ij/, Bethesda, Maryland.

Rengasamy P (2010) Soil processes affecting crop production in salt-affected soils. Funct Plant Biol 37:613-620.

Rønsted N, Chase MW, Albach DC, Bello MA (2002). Phylogenetic relationships within Plantago (Plantaginaceae): evidence from nuclear ribosomal ITS and plastid trnL-F sequence data. Bot J Lin Soc 139:323-338.

Tutel B, Kandemir I, Kuş S, Kence A. (2005). Classification of Turkish Plantago L. species using numerical taxonomy. Turk J Bot 29:51-61.

Vicente O, Boscaiu M, Naranjo MA, Estrelles E, Bellés JM, Soriano P (2004). Responses to salt stress in the halophyte Plantago crassifolia (Plantaginaceae). J Arid Environ 58:463481.

Xiong L, Zhu JK (2002). Salt-stress signal transduction, p. 165197. In: Scheel D, Wasternack C (Eds.). Plant Signal Transduction, Frontiers in Molecular Biology Series. Oxford University Press, Oxford UK.

Zhu J-K (2000). Genetic analysis of plant salt tolerance using Arabidopsis. Plant Physiol 124:941-948.

Zhu J-K (2001). Plant salt tolerance. Trends Plant Sci 6:66-71. 

